\title{
Integrated Energy System Planning Optimization Considering Equipment Performance
}

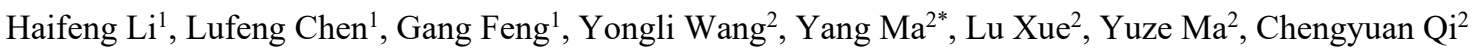 \\ ${ }^{1}$ Economic and Technological Research Institute of State Grid Xinjiang Electric Power Co., Ltd, Xinjiang 830000, China \\ 2 Departments of Economics and Management, North China Electric Power University, Beijing 102206, China
}

\begin{abstract}
At present, regional integrated energy system is considered as a novel form to improve the comprehensive energy efficiency and economy of the system by integrating multiple energy subsystems. The key link of integrated energy system planning and optimization is to determine the kind and installed capacity of source-side equipment, and how to make the equipment of the system cooperate and couple with each other. A model of equipment capacity allocation at the source side of integrated energy system is proposed, which can get the best equipment kind and installed capacity in the planning and optimization area. The objectives of the model are the optimal economy and the minimum carbon emission. In order to verify the effectiveness of the model proposed in this paper, three typical scenarios are set for comparative analysis. In the simulation, by comparing the economy and carbon emission of planning results in different scenarios, it can be found that there is a potential connection between the installed capacity of source-side equipment, and at the same time, the carbon emission will also affect the installed capacity of equipment. Renewable energy equipment has made great contribution to carbon emission, but its investment cost has greatly increased the system planning cost. Therefore, system economy and carbon emission are mutually exclusive to a certain extent.
\end{abstract}

\section{Introduction}

Because of the scarcity and non-renewable nature of energy resources, which is related to the development of the country and the improvement of the national economic level, we need to improve the utilization efficiency of energy and the coupling and complementarity of multiple energy sources. [1]. Since the 21st century, China's social economy has developed rapidly, the total energy demand has increased dramatically, there is a serious imbalance between the demand side and the supply side [2]. China's enpenditure of energy per unit Gross Domestic Product is 0.55 tons of standard coal/10,000 yuan, which is still 1.4 times of the world average level of energy consumption intensity and 2.1 times of the average energy consumption in developed countries such as Japan and the United States [3]. In recent years, environmental pollution problems such as smog and sewage discharge caused by traditional energy production and consumption are still serious [4].

Integrated energy system is the integration of multiple energy subsystems. How to match each subsystem and consider the coupling and complementarity in the planning and optimization of regional integrated energy system, coordination planning is the key point, such as the coupling among electrical system, thermal system, cold system and gas system, including electro-thermal coupling, electrical coupling and electro-thermal coupling. The coupling between different energy subsystems is of great significance to the development of integrated energy system. On the basis of establishing the planning model of CCHP, the paper [5] puts forward the optimal collocation scheme of modular equipment such as gas turbine, waste heat boiler and lithium bromide refrigerator. Literature [6] puts forward a network enhancement model based on threelevel robust optimization, which can reduce the possibility of reducing economy and environmental protection in the worst case. Literature [7] has formed an optimization scheme of coupling and complementation of electro-thermal coupling system across time and space, and analyzed the potential of cooperative optimization of subsystems.

Under the national call of "Jinshan Yinshan is not as good as green water and green hills", the integrated energy system has also landed in various energy projects with the goal of "two highs and three lows", namely, improving the comprehensive energy efficiency, reliability, operation cost, carbon emission and pollutant emission of the system. Literature [8] introduces the calculation method of carbon emission and puts forward the trading model of carbon emission rights. Literature [9] puts forward a multi-objective programming optimization model, and analyzes the sensitivity of the comprehensive energy efficiency, economy and carbon emission of the system to the model. This paper puts forward a method to determine the economic dispatch of

\footnotetext{
*Corresponding author: mayuzebj@163.com
} 
power system in consideration of economy. Through the above research, the role of multi-objective in the planning and optimization of integrated energy system can maximize the coordination and optimization of the system. At the same time, due to the importance of carbon emissions in the energy field, carbon emissions trading has become the future object of electricity market trading.

\section{Description of IES Planning Problems}

Integrated energy subsystem model can be realized through energy hub. The energy hub can connect the demand side and the supply side together, and at the same time, the energy conversion, coordination and complementarity between the energy supply equipment at the source side can be completed in the energy hub. The input ports of energy hub are usually composed of power grid, gas grid, heat grid and cold grid, and the output ports are directly connected to the electricity, heat, cold and gas load demands of users. However, it is also possible to configure energy storage equipment to absorb excess electricity and make better use of the peak time electricity price policy to store the valley price period into the battery and release it during the peak period to meet the electricity demand of the park.

Of course, the prerequisite for the planning and optimization of integrated energy system is to meet the balance between supply and demand. At this time, the coupling complementarity and collaborative optimization of various subsystems and equipment are introduced, so as to achieve the purpose of improving the comprehensive energy efficiency, reducing the system operation cost, reducing the system carbon emissions and improving the system reliability. The model gives the optimal structural planning results from the aspects of the types of conversion devices and energy storage devices, capacity selection and the optimal scheme of comprehensive energy planning optimization.

\section{IES planning and optimization model}

\subsection{Model of typical multi-energy coupling equipment}

CCHP can generate electricity in gas turbine, realize heating by waste heat boiler unit and refrigerate by lithium bromide reactor. Because it realizes the purpose of energy cascade utilization, CCHP is one of the energy conversion equipment to be selected for comprehensive energy system planning and optimization. The mathematical model formula is:

$$
\left\{\begin{array}{l}
P_{\text {ele }, \text { CCHP }}(t)=P_{\text {gas }, C C H P}(t) \eta_{e} \\
P_{\text {cold }, C C H P}(t)=P_{\mathrm{r} \text { est }- \text { ele }, C C H P}(t) K_{c} \\
P_{\text {heat }, C C H P}(t)=P_{\text {gas }, C C H P}(t) \eta_{C C H P}^{H}\left(1-\eta_{C C H P}^{\text {Loss }}\right) \\
\eta_{C C H P}=\frac{E_{P}(t)+E_{C}(t)+E_{H}(t)}{F_{C C H P}(t) H_{\text {low }}} \\
\eta_{R E R}=\frac{P_{\text {ele }, C C H P}(t)+P_{\text {cold }, C C H P}(\mathrm{t})+P_{\text {heat }, \mathrm{CCHP}}(\mathrm{t})}{F_{C C H P}(t) H_{\text {low }}} \Delta t
\end{array}\right.
$$

In the formula: $P_{e l e, C C H P}(t), P_{g a s, C O H P}(t)$ and $\eta_{e}$ respectively represent the power generation power, natural gas consumption power and operation conversion efficiency of the internal combustion engine at time t; $\eta_{C C H P}, E_{P}(t), E_{C}(t), E_{H}(t), F_{C C H P}(t)$ and $\eta_{C C H P}^{\text {Loss }}$ represent system efficiency, electricity, cold, heat, input, respectively The total amount of fuel in the CCHP system and the heating value of the fuel at lower levels; $\eta_{\text {RER }}, P_{\text {ele }}$ CCHP $(t), P_{\text {cold }, C C H P}(\mathrm{t}), P_{\text {heat }, \mathrm{CCHP}}(\mathrm{t})$ and $\Delta \mathrm{t}$ represent the raw material energy efficiency of the CCHP system, the electrical power output by the system, the cooling power, the thermal power, and the conversion period, respectively.

\subsection{Objective function}

(1) Objective function I:

The optimal economy of IES is to minimize the operation cost. The objective function with optimal economy includes the cost of purchasing equipment, equipment operation and energy cost. The economic objective function designed according to the scale and characteristics of typical scenes is as follows:

$$
\begin{aligned}
& F_{1}=\min C_{o p}=C_{o p-E}+C_{o p-H}+C_{o p-N G} \\
& C_{o p-E}=\sum_{i=1}^{n} C_{i} P_{i}(t)+C_{b a t, d e p}+\left(M \gamma_{e l e-d r}+(1-M) \gamma_{e l e}\right) P_{E B_{-} \text {grid }}(t) \\
& C_{o p-H}=C_{\mathrm{HB} g r i d}+a_{h_{-} s t} P_{h_{-} s t}(t) \\
& C_{o p-N G}=\left(N \partial_{\text {fuel-dr }}+(1-N) \partial_{\text {fuel }}\right) \frac{\sum P_{C C H P}(t) \Delta t}{\delta_{C C H P} \times L H V_{N G}}+a_{N G_{-} s t} P_{N G_{-} s t}(t)
\end{aligned}
$$

Where $C_{o p-E}, C_{o p-H}, C_{o p-N G}$ and is the operation cost of power, heat energy and NG supply module, yuan; $\gamma_{\text {ele-dr }}$ is the electricity price of DR, yuan $/ \mathrm{kWh} ; C_{b a t, d e p}$ is the charge / discharge depreciation cost per unit time of energy storage, yuan $/ \mathrm{kWh} ; \partial_{\text {fuel-dr }}$ is the $\mathrm{NG}$ price of $\mathrm{DR}$, yuan $/ \mathrm{m}^{3} ; L H V_{N G}$ is the low calorific value of natural gas, $\mathrm{kWh} / \mathrm{m}^{3}$.

(2) Objective function II:

The carbon emission sources of the system are the system cogeneration units and gas-fired boiler units, whose fuel is mainly natural gas, and carbon dioxide is the main emission. Therefore, the carbon emission function also calculates the carbon dioxide emissions backwards according to the fuel consumption of the two kinds of equipment. This paper also considers the cost of excessive carbon emissions, and gas also has a certain impact on the system economy. Therefore, the carbon emission objective function is as follows: 


$$
F_{2}=\min C_{E}=\sum_{k=1}^{w} \sum_{j=1}^{m} P_{k}(t) \varpi_{k, j} \delta_{E, j}+\zeta_{E C-p}
$$

Where $C_{E}$ is the environmental cost, yuan; $P_{k}(\mathrm{t})$ is the power of the emission source $\mathrm{k}$ at time $\mathrm{t}, \mathrm{kw} ; \varpi_{k, j}$ is the emission coefficient of the pollutant $\mathrm{j}$ from the emission source $\mathrm{k}, \mathrm{kg} / \mathrm{kW} ; \zeta_{E C-p}$ is the penalties for the punishment of pollutants.

\section{Case study}

\subsection{Data}

In this paper, a regional comprehensive energy planning optimization project in China is taken as a simulation example to verify the effectiveness of the proposed model. According to the historical illumination and wind speed of the park, it is taken as the input parameters of photovoltaic fan. Through on-the-spot investigation, the local natural gas price is 3.23 yuan/cubic meter, the heat energy price is $0.22 \mathrm{yuan} / \mathrm{kWh}$, and the time-of-use electricity price is $0.45 \mathrm{yuan} / \mathrm{kWh}$ at $1: 00-5: 00$ in valley time, 6: 00-9: 00 and 14:00-16: 00 in flat section, and 0.98 yuan in electricity price The forecast curves of electricity and heat load on typical days of the park are shown in Figure 1.

In order to adapt to the MATLAB program environment and improve the simulation calculation speed, the upper and lower limits of the installed capacity of gas turbines are $500 \mathrm{~kW}$ and $1500 \mathrm{~kW}$ respectively. The economy of photovoltaic units needs to be considered, so it is not as big as possible. Its floor area seriously affects the total planning cost of the park, and its installed capacity is 1.5 million and $500 \mathrm{~kW}$ respectively. The upper and lower limits of fan units are $500 \mathrm{~kW}$ and $1500 \mathrm{~kW}$. The battery capacity is limited to $3 \mathrm{MW}$, and the heat storage tank capacity is set to $2 \mathrm{MW}$. The simulation is solved by genetic algorithm. The internal parameters of the algorithm are crossover rate of 0.95 , mutation rate of 0.15 , initial population number of 800 and iteration times of 150 .

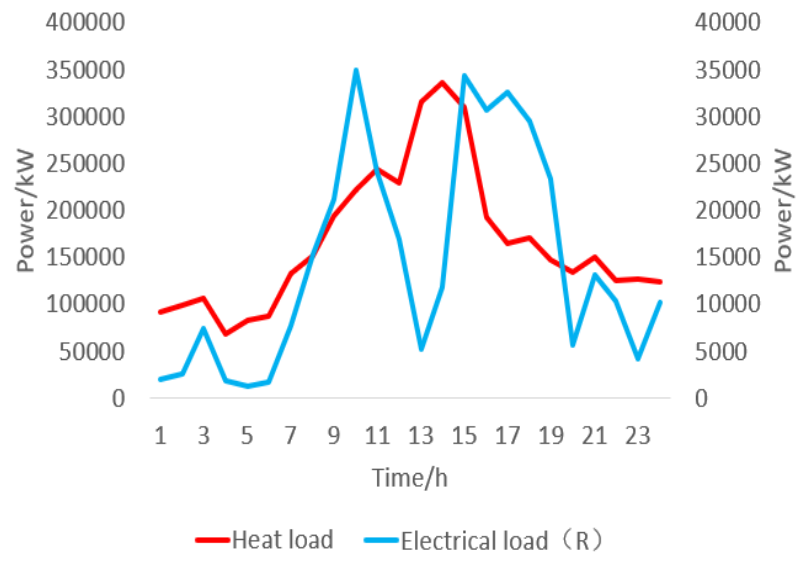

Fig. 1. Typical forecasting curves of daily electricity and heat load

\subsection{Planning optimization simulation and results}

It can be seen from Table 1 that compared with Scenes 2 and 3, Scenario 1 has the largest carbon emission. The main reason is that in scenario 1 , the installed capacity of CCHP units is large, which contributes to the park economically, but the increase of its capacity brings a lot of carbon emissions, which is contrary to the goal 2 of the model proposed in this paper; Compared with the other two scenarios, scenario 2 is in the middle position in terms of economy and carbon emissions, neither the best nor the worst; Scenario 3, which is consistent with the model proposed in this paper, is superior to the other two scenarios in economy and carbon emission. In the system equipment planning, not only economy or carbon emission is considered, but two goals are taken as the basis of planning to choose strategies. Therefore, it can prove the effectiveness and field operability of the model proposed in this paper. At the same time, this paper found that CCHP units can significantly improve the economy and comprehensive energy efficiency of the system, but it will play a serious negative role in the carbon emission target.

Table 1. Simulation results of three scenarios

\begin{tabular}{|c|c|c|c|}
\hline Scene & $\mathbf{1}$ & $\mathbf{2}$ & $\mathbf{3}$ \\
\hline Economy & 17595631 & 1865447.33 & 16834256.19 \\
\hline $\begin{array}{c}\text { Carbon } \\
\text { emissions }\end{array}$ & 8564231.23 & 7965478.64 & 7897695.67 \\
\hline
\end{tabular}

\section{Conclusion}

This paper describes the problem of multi-objective comprehensive energy planning considering equipment performance, and proposes an optimization model of comprehensive energy system planning based on economy and carbon emission. On the basis of NSGA-II algorithm, the reasonable allocation scheme of energy supply equipment capacity is solved. In addition, in order to verify the effectiveness of the proposed optimization model for capacity allocation planning of IESs, we take a domestic park as an example for simulation verification. The planning proposed in this paper and the planning scheme in 3 have been well applied in the park. The results show that the proposed scheme 3 is better than 2 and 1 in combination with economy and carbon emission. In the future, I will further study the capacity planning and equipment location of IES in order to realize the optimal allocation and location of equipment capacity of IES. Not only to realize the economic optimization and the minimization of carbon emissions, but also to realize the maximization of energy efficiency and the maximization of system reliability.

\section{References}

1. Song C, Jing W, Zeng P, Rosenberg, C. An analysis on the energy consumption of circulating pumps of residential swimming pools for peak load management [J]. Applied Energy, 2017, 195:1-12. 
2. Yu Xiaodan, Xu Xiandong, Chen Shuoyi, et al. A brief review to IES and energy internet [J]. Transactions of China Electrotechnical Society, 2016, 31(1):1-13.

3. Stanislav P, Bryan K, TihomirR M . Smart grids better with IES[C]/Proceedings of the Electrical Power \& Energy Conference (EPEC). Montreal, Canada, 2009.

4. Frédéric Colas, Lu D, Lazarov V , Bruno François, Kanchev H. Energy management and power planning of a microgrid with a PV-based active generator for Smart Grid Applications [J]. IEEE Transactions on Industrial Electronics, 2011, 58(10):4583-4592.

5. Ali H, Yilbas B S, Al-Sharafi A. Innovative design of a thermoelectric generator with extended and segmented pin configurations [J]. Applied Energy, 2017, 187:367-379.

6. Copiello S. Expansion of the italian natural gas network to the Sardinia island: Economic assessment [J]. Journal of Natural Gas Science \& Engineering, 2018, 54:297-308.

7. Zheng J, Zhou Z, Zhao J, Wang J. Integrated thermal and power dispatch truly utilizing thermal inertia of district thermaling network for wind power integration [J]. Applied Energy, 2018, 211:865-874.

8. Qadrdan M, Chaudry $\mathrm{M}, \mathrm{Wu}$ J, Jenkins $\mathrm{N}$, Ekanayake J. Impact of a large penetration of wind generation on the GB gas network [J]. Energy Policy, 2010, 38(10):5684-5695.

9. He C, Dai C, Wu L, Liu T. Robust network hardening strategy for enhancing resilience of integrated electricity and natural gas distribution systems against natural disasters [J]. IEEE Transactions on Power Systems, 2018, 33(5):57585798. 